\title{
Analysis of Phytochemical Composition and Biological Activities of Verbascum cheiranthifolium var. cheiranthifolium stem and flowers
}

\author{
Abdullah Dalar ${ }^{(i)}{ }^{*}$, Aydin Sukru Bengu ${ }^{2}$, Oruc Allahverdiyev ${ }^{3}$ \\ ${ }^{1}$ Department of Pharmaceutical Botany, Faculty of Pharmacy, Van Yuzuncu Yil University, Van, Turkey \\ ${ }^{2}$ Department of Medical Services and Techniques, Vocational School of Health Services, University of Bingol, \\ Turkey \\ ${ }^{3}$ Department of Pharmacology, Faculty of Pharmacy, Van Yuzuncu Yil University, Van, Turkey
}

\begin{abstract}
Within this study phytochemical composition, antioxidant and enzyme inhibitory activities of extracts obtained from stem and flower of Verbascum cheiranthifolium var. cheiranthifolium were analysed. Both of the extracts were detected as rich sources of phenolics (verbascoside and luteolin hexoside), various volatile and fatty acid compounds. Luteolin hexoside rich stem extract had pronounced FCR, FRAP and $\alpha$-glucosidase inhibitory activities. Flower extract had high levels of ORAC assay and effectively suppressed activity of pancreatic lipase enzyme, which was rich in verbascoside compound. Phenolic compounds and volatile compounds present in the extracts might be the main contributors of antioxidant capacity and enzyme inhibitory activities of the stem and flower extracts. Pronounced antioxidant and enzyme inhibitory activities and rich bioactive composition determined in this study reveal that Verbascum cheiranthifolium var. cheiranthifolum extracts might be a good source for natural health attributing sources.
\end{abstract}

\section{ARTICLE HISTORY}

Received: 03 March 2018

Revised: 26 April 2018

Accepted: 04 August 2018

\section{KEYWORDS}

Antioxidant, $\alpha$-Glucosidase, Pancreatic Lipase, Phenolics, Volatiles

\section{INTRODUCTION}

Verbascum species belong to Scrophulariaceae family are commonly known as mullein and compromise of approximately 250 taxa worldwide. Decoctions, infusions or poultice prepared from mullein species have been employed in folk medicine for their curative properties in the treatment a wide range of ailments such as asthma, haemorrhoids, rheumatic pain, earache, abdominal pain, eczema etc. [1-2]. Multiple species of mullein are commonly used as a plant based nutritional supplement and herbal tea [3].

Phytochemical compounds diversity and health attributing properties of mullein species were reported by multiple researchers. It was reported that Verbascum species contained a wide 
range of bioactive compounds such as saponins, glycosides, phenolics, steroids, alkaloids and polysaccharides [1], which were among the main contributors of in vitro and in vivo biological activities including antimicrobial, antimalarial, antioxidant, antiinflammatory, antinociceptive, antitumor, anticancer, cytotoxic, antiulcerogenic, antihepatotoxic, antitussive etc. [3-5].

Verbascum cheiranthifolium var. cheiranthifolium known as sığırkuyruğu has been extensively utilized by local people in Turkey. Though, there were multiple reports in scientific literature regards to chemical content and biological activities of Verbascum cheiranthifolium var. cheiranthifolium, those studies generally focused on selected plant parts (particularly leaf) and limited chemical composition and biological activities investigations. Therefore, we aimed to analyse extracts obtained from stem and flowers of Verbascum cheiranthifolium var. cheiranthifolium in the context of chemical composition, antioxidant capacity and enzyme inhibitory activities comprehensively.

Within this study, chemical composition was investigated via HPLC-MS/MS (for total and individual phenolics) and GC-MS (for volatiles and fatty acids). Antioxidant capacity was examined by performing complementary antioxidant methods including Folin-Ciocalteu reducing (FCR), Ferric reducing antioxidant power (FRAP) and Oxygen radical absorbance capacity (ORAC). Enzyme inhibitory activities of the extracts were measured towards selected enzymes (pancreatic lipase and $\alpha$-glucosidase) isolated from mammalians.

\section{METHOD}

\subsection{Plant Material}

Verbascum cheiranthifolium var. cheiranthifolium (Scrophulariaceae) stem and flower samples with no apparent physical damage were collected from Konalga village, Çatak/Van city, in the Eastern Anatolia Region of Turkey, on August 12 $2^{\text {th }}, 2017$ (GPS coordinates $37^{\circ} 51^{\prime}$ $255^{\prime \prime} \mathrm{N} 043^{\circ} 09^{\prime} 857^{\prime \prime E}$ ). Plant materials were isolated in clean polythene bags and transferred to laboratory within a maximum of $2 \mathrm{~h}$ after harvest. The identity of plant material was confirmed at Van Pharmaceutical Herbarium, Pharmacy Faculty, Van Yuzuncu Yil University, Turkey and a voucher specimen was stored at the university's herbarium (Herbarium code: VPH-238; Collector code: MM204). The plant materials were properly cleaned from dust and contaminants by minimizing the loss of bioactive components and left at room temperature in the dark until dry. The plant materials were subsequently ground for a fine powder and stored at $-20{ }^{\circ} \mathrm{C}$ until analysed.

\subsection{Reagents}

Unless otherwise stated, all chemicals were purchased from Sigma-Aldrich (Istanbul, Turkey) and were of analytical or HPLC grade. Acarbose was purchased as 'glucobay' from Bayer (Bayer, Turkey). Folin-Ciocalteu was purchased from Merck (Darmstadt, Germany).

\subsection{Preparation of lyophilized extract}

The ethanol-based lyophilized extracts were prepared as described previously [6]. Briefly, the ground plant material was mixed with a 20 -fold volume of acidified ethanol $(80 \%$ ethanol, $19 \% \mathrm{H}_{2} \mathrm{O}$ and $1 \%$ of $0.1 \%$ trifluoroacetic acid, $\left.\mathrm{v} / \mathrm{v} / \mathrm{v}\right)$, shaken for $2 \mathrm{~h}$ at room temperature $\left(22^{\circ} \mathrm{C}\right)$ and centrifuged for $20 \mathrm{~min}$ at $15320 \mathrm{~g}(10000 \mathrm{rpm})$ at $4^{\circ} \mathrm{C}$ with the supernatant collected. The extraction was repeated one more time. The supernatants from the consecutive extractions were combined and the solvent evaporated under reduced pressure at $37^{\circ} \mathrm{C}$ using a rotary evaporator (Rotavapor R-205; Buchi, Switzerland). The derived fraction was dissolved in purified water and freeze-dried under a vacuum at $-51^{\circ} \mathrm{C}$ to obtain a fine lyophilized powder. 


\subsection{Antioxidant capacity}

\subsubsection{Folin-Ciocalteu reducing capacity}

Folin-Ciocalteu reducing capacities (Total phenolic content) of the extracts were determined as described previously [6] and the results were expressed as mg gallic acid equivalents per gram of dry weight of the lyophilized extract (mg GAE/g DW), based on Gallic acid standard curve and against a blank control. The analyses were conducted in triplicate.

\subsubsection{Ferric reducing antioxidant power}

Total reducing capacity was determined using the FRAP assay as described previously [6] and the reducing capacities of the extracts were expressed as $\mu \mathrm{M}$ of iron (Fe2+) per gram of dry weight of lyophilized extract $\left(\mu \mathrm{M} \mathrm{Fe}^{+2} / \mathrm{g} \mathrm{DW}\right)$ based on an iron sulphate standard $\left(\mathrm{Fe} 2 \mathrm{SO}_{4}\right)$ curve against a blank control. The analyses were conducted in triplicate.

\subsubsection{Oxygen radical absorbance capacity}

Oxygen radical scavenging capacity was determined using the ORAC assay as described previously [6] and antioxidant capacities of the samples were expressed as $\mu \mathrm{M}$ of trolox equivalent per gram of dry weight of lyophilized extract ( $\mu \mathrm{M} \mathrm{T} \mathrm{Eq./g} \mathrm{DW)} \mathrm{based} \mathrm{on} \mathrm{a} \mathrm{trolox}$ standard curve. The analyses were conducted in triplicate.

\subsection{Inhibitory activities towards selected enzymes}

\subsection{1. $\alpha$-Glucosidase inhibitory activity}

The inhibition of $\alpha$-glucosidase (obtained from intestinal acetone powders from rat) was determined was determined as described previously [6], using sucrose ( $2 \mathrm{~g}$ of sucrose in $100 \mathrm{ml}$ of maleic acid buffer) as a substrate. The relative $\alpha$-glucosidase inhibition was calculated using the following formula: \% Inhibition $=[((\mathrm{ACB}-\mathrm{AC})-(\mathrm{ASB}-\mathrm{AS})) /(\mathrm{ACB}-\mathrm{AC})] \mathrm{x} 100$, where $\mathrm{AS}$ and $\mathrm{AC}$ were the absorbance of sample and negative control, and where ASB and ACB were the absorbance of sample blank and control blank, respectively. The absorbance was measured at $505 \mathrm{~nm}$ using a Shimadzu 1601 spectrophotometer (Tokyo, Japan).

\subsubsection{Pancreatic lipase inhibitory activity}

The lipase inhibitory activity was assayed as described previously [6], using 4methylumbelliferyl oleate $(0.1 \mathrm{mM})$ as a substrate, with the exception of porcine pancreatic lipase (Sigma type II), which was prepared using a concentration of $0.085 \mathrm{~g} / \mathrm{ml}$. The relative lipase inhibition activity was calculated using the following formula: \% Inhibition $=(1-$ (FSFSB) / (FC-FCB)) x100, where FS and FC were the values of samples and negative control measured fluorometrically at an emission wavelength of $460 \mathrm{~nm}$ and excitation of $320 \mathrm{~nm}$ with slit widths of $5 \mathrm{~nm}$ (POLARstar Omega, BMG Labtech, Germany), and where FSB and FCB were the fluorescence readings of sample blank and control blank, respectively.

\subsection{Analysis of phenolic compounds}

Identification and quantification of phenolic compounds by high liquid chromatography - diode array - mass spectrometry (HPLC-DAD-MS/MS) analysis were conducted as described previously [6]. The amount of total phenolic compounds detected at $280 \mathrm{~nm}$ were quantified as mg Gallic acid equivalents per gram weight of the extract (mg GA Eq./g DW) based on Gallic acid calibration curve (concentration range: $0.0125-0.5 \mathrm{mg} / \mathrm{mL} ; \mathrm{r}^{2}=1$ ). Total phenolic compounds detected at $326 \mathrm{~nm}$ were calculated as $\mathrm{mg}$ of Chlorogenic acid equivalents per gram dry weight of the extract (mg CHA Eq./g DW) based on Chlorogenic acid calibration curve (concentration range: $0.0125-0.5 \mathrm{mg} / \mathrm{mL} ; \mathrm{r}^{2}=1$ ). Total phenolics content detected at $370 \mathrm{~nm}$ were quantified as mg Rutin equivalent per gram dry weight of the extract (mg Rutin Eq./g DW) based on the Rutin calibration curve (concentration range: $0.0125-0.5 \mathrm{mg} / \mathrm{mL} ; \mathrm{r}^{2}=0.999$ ). 


\subsection{Analysis of volatile and fatty acid compounds}

Volatile compounds and fatty acids present in extracts were analysed by gas chromatography mass spectrometry (GC/MS) using a head space solid phase micro extraction and identified by the fragment ions and relative retention indices of their peaks with those of the MS library standards as described previously [7].

\subsection{Data Analysis}

The mean of results was calculated based on at least three independent evaluations $(n=3)$ and the standard deviations (SD) were also calculated. IC-50 values were calculated from the corresponding dose inhibition curve according to their best-fit shapes based on at least four reaction points using Microsoft Excel. Statistical correlation analyses were performed using Graphpad Prism 5 (Graphpad Software, CA, USA), which were considered statistically significant when the $\mathrm{p}<0.05$.

\section{FINDINGS}

\subsection{Antioxidant and enzyme inhibitory activities}

Table 1 presents antioxidant capacities and enzyme inhibitory levels of the extracts. Stem extract exhibited higher FCR and FRAP levels than that of the flower extract. On the contrary to FCR and FRAP, the ORAC value of flower extract was higher than that of the stem extract. With regards to enzyme inhibitory levels, both extracts showed mild inhibitory activities against $\alpha$-glucosidase, which was lower than Acarbose (commercially used $\alpha$-glucosidase inhibitor agent). However, the extracts particularly flower extract showed pronounced inhibitory activities against pancreatic lipase and showed high amounts of Orlistat equivalents (Table 1).

Table 1. Antioxidant and enzyme inhibitory activities

\begin{tabular}{|c|c|c|c|c|}
\hline & & & Stem & Flower \\
\hline \multirow{3}{*}{ 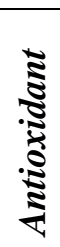 } & \multirow{3}{*}{ 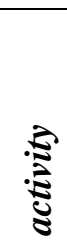 } & $\mathrm{FCR}^{1}$ & $76.5 \pm 2.0 \mathrm{a}$ & $68.3 \pm 1.2 \mathrm{~b}$ \\
\hline & & FRAP $^{2}$ & $1110.4 \pm 36.1 \mathrm{a}$ & $490.0 \pm 3.5 b$ \\
\hline & & ORAC $^{3}$ & $4494.2 \pm 76.8 b$ & $5073.3 \pm 71.6 \mathrm{a}$ \\
\hline \multirow{6}{*}{ 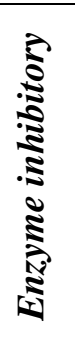 } & \multirow{6}{*}{ 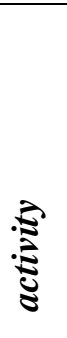 } & $\alpha$-Glucosidase inhibition & & \\
\hline & & $\mathrm{IC} 50^{4}(\mathrm{mg} / \mathrm{ml})$ & $2.15 \pm 0.06 \mathrm{a}$ & $4.90 \pm 0.09 \mathrm{~b}$ \\
\hline & & Acarbose Eq. $(\mu \mathrm{mol} / \mathrm{g} \mathrm{DW})$ & $21.46 \pm 0.58 \mathrm{a}$ & $9.40 \pm 0.17 \mathrm{~b}$ \\
\hline & & Pancreatic lipase inhibition & & \\
\hline & & $\mathrm{IC} 0^{4}(\mathrm{mg} / \mathrm{ml})$ & $1.81 \pm 0.03 b$ & $0.46 \pm 0.05 \mathrm{a}$ \\
\hline & & Orlistat Eq. $(\mu \mathrm{mol} / \mathrm{g} \mathrm{DW})$ & $1.52 \pm 0.02 b$ & $6.11 \pm 0.73 \mathrm{a}$ \\
\hline
\end{tabular}

Means with different letters in the same raw were significantly different at the level $(\mathrm{p}<0.05) ; \mathrm{n}=3$.

${ }^{1}$ Total phenolics content (Folin-Ciocalteu values) - mg Gallic acid Equivalent/g DW,

${ }^{2}$ Ferric reducing antioxidant power $-\mu \mathrm{mol} \mathrm{Fe}{ }^{2+} / \mathrm{g} \mathrm{DW}$,

${ }^{3}$ Oxygen radical absorbance capacity - $\mu$ mol Trolox Equivalent/g DW.

${ }^{4}$ IC50-Half minimal inhibitory concentration.

\subsection{Chemical Composition}

Extraction yields (\%), total phenolics and individual phenolic compounds were presented in Table 2. The flower extract yielded two times higher extraction than that of the stem. The total phenolic levels of extracts contained the highest amounts of phenolics at $326 \mathrm{~nm}$. No any compounds were detected at $520 \mathrm{~nm}$. Spectral characteristics of HPLC peaks (Figure 1) 
revealed that phenolics were the dominating group of hydrophilic compounds. Mass spectrometric data confirmed these results (Table 2).

The major phenolic compound present in stem extract and second major compound of the flower ex tract had positively charged molecular ion $\left([\mathrm{M}+1]^{+}\right)$at $\mathrm{m} / \mathrm{z} 449$ and negatively charged molecular ion $\left([\mathrm{M}-1]^{-}\right)$at $\mathrm{m} / \mathrm{z} 447$, respectively and MS/MS fragments were at $\mathrm{m} / \mathrm{z} 287$ and 285 , respectively. The neutral loss of $162 \mathrm{amu}$ indicates the presence of hexoside unit. On the basis of molecular weight, fragmentation pattern and absorbance spectrum, this compound was tentatively identified as luteolin hexoside. This compound made up over $52 \%$ of total phenolics (Table 2).

The dominated phenolic compound in the flower extract was identified as verbascoside based on $\mathrm{m} / \mathrm{z}$ transition data and spectral and absorbance characteristics of HPLC peaks of the flower extract since it's negatively charged molecular ion ([M-1] $\left.]^{-}\right)$at $\mathrm{m} / \mathrm{z} 623$ and MS/MS fragments at $\mathrm{m} / \mathrm{z} 461$ (Table 2). This compound made up over $52 \%$ of total phenolics of the flower extract. Additionally, the flower extract contained luteolin hexoside as the second major phenolic compound of contributing $9.6 \%$ of total phenolics (Table 2, Figure 1). Other phenolic compounds tentatively identified in both extracts based on $\mathrm{m} / \mathrm{z}$ transition data were apigenin, chlorogenic acid, apigenin glucoside, quercetin hexoside and rutin at trace levels (Table 2).

Table 2. Mass spectrometric details and concentration of phenolic compounds

\begin{tabular}{|c|c|c|c|c|}
\hline \multicolumn{3}{|l|}{ Yields and Total Phenolics } & Stem & Flower \\
\hline \multicolumn{3}{|l|}{ Yields (\%) } & $14.0 \pm 0.8 \mathrm{~b}$ & $30.3 \pm 1.3 \mathrm{a}$ \\
\hline \multicolumn{3}{|l|}{ Total Phenolics at $280 \mathrm{~nm}^{1}$} & $65.3 \pm 2.0 \mathrm{~b}$ & $84.1 \pm 0.4 \mathrm{a}$ \\
\hline \multicolumn{3}{|l|}{ Total Phenolics at $326 \mathrm{~nm}^{2}$} & $88.6 \pm 0.7 \mathrm{a}$ & $121.2 \pm 0.7 \mathrm{a}$ \\
\hline \multicolumn{3}{|l|}{ Total Phenolics at $370 \mathrm{~nm}^{3}$} & $48.5 \pm 4.2 \mathrm{a}$ & $32.9 \pm 2.2 b$ \\
\hline \multirow[b]{2}{*}{ Individual phenolic compounds } & \multicolumn{2}{|l|}{ MS/MS } & & \\
\hline & $\overline{[\mathrm{M}+1]^{+} /[\mathrm{M}-1]^{-}}$ & Fragments & & \\
\hline$\overline{\text { Apigenin }^{4}}$ & $-/ 269$ & $-/ 117$ & $\mathrm{~T}$ & $\mathrm{~T}$ \\
\hline Chlorogenic acid ${ }^{4,3}$ & $-/ 353$ & $-/ 191$ & $\mathrm{~T}$ & $\mathrm{~T}$ \\
\hline Apigenin glucoside ${ }^{5}$ & $-/ 431$ & $-/ 269$ & $\mathrm{~T}$ & $\mathrm{~T}$ \\
\hline Luteolin-7-O-glucoside ${ }^{5,6}$ & $449 / 447$ & $287 / 285$ & $46.4 \pm 0.2 \mathrm{a}$ & $11.7 \pm 0.1 \mathrm{~b}$ \\
\hline Quercetin/hesperitin glucoside ${ }^{5,6}$ & $465 /-$ & $303 /-$ & $\mathrm{T}$ & $\mathrm{T}$ \\
\hline Quercetin rutinoside (Rutin) ${ }^{4}$ & $611 / 609$ & $303 / 301$ & $\mathrm{~T}$ & $\mathrm{~T}$ \\
\hline Verbascoside $^{4}$ & $-/ 623$ & $/ 461$ & $\mathrm{~T}$ & $63.4 \pm 0.1$ \\
\hline
\end{tabular}




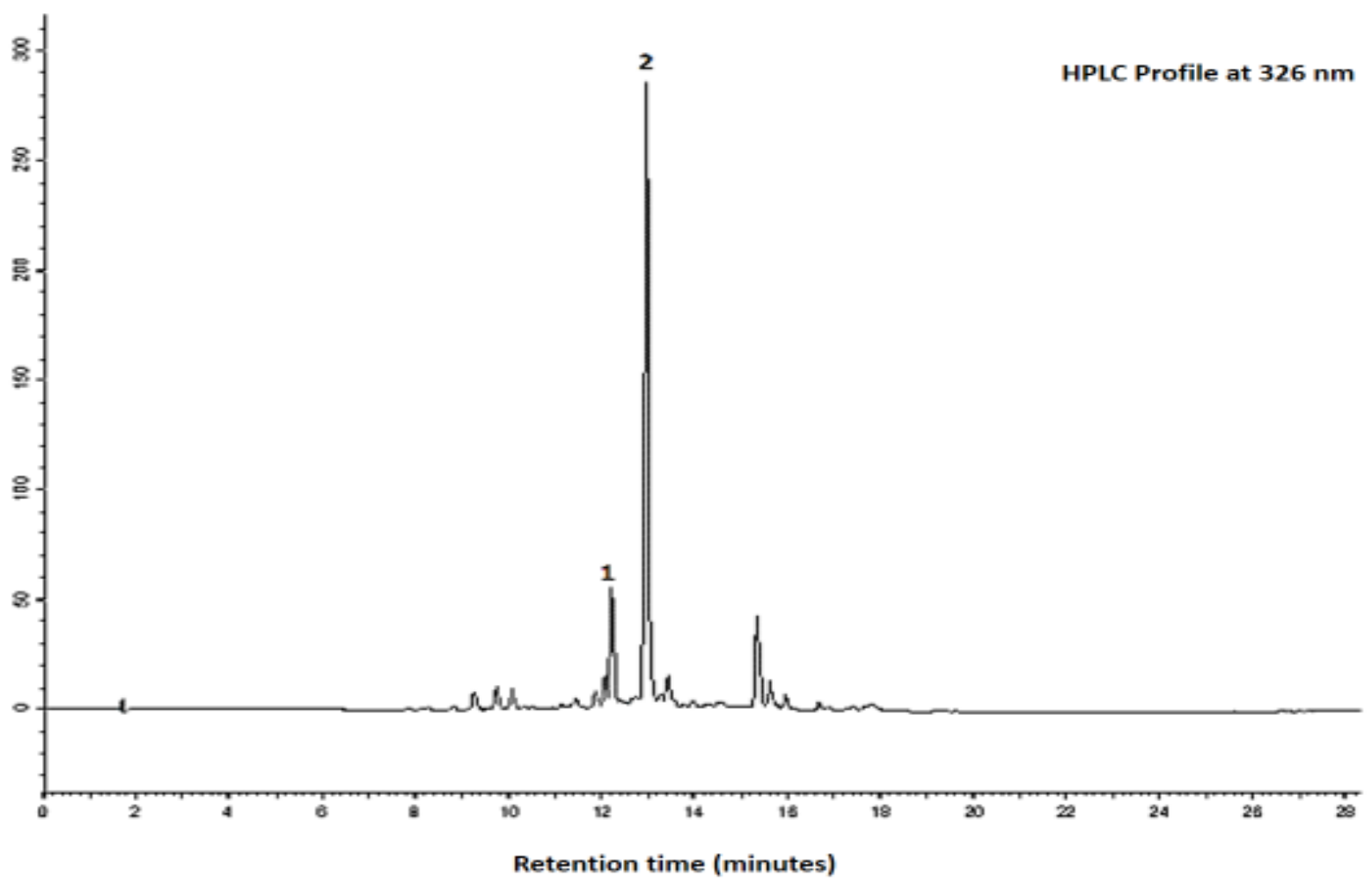

Figure 1. Representative HPLC chromatogram of extracts: (1) Luteolin-7-O-glucoside, (2) Verbascoside.

As presented in Table 3 and Figure 2, the extracts had a rich composition of volatile and fatty acids. GC-MS analysis revealed that nonanal, 2-undecenal, 2-decenal, palmitic acid ethyl ester and oleic acid ethyl ester were determined as the major volatile compounds of the extracts. Flower extract also contained 2,6-Di-tert butylphenol and 9,12-octadecadienoic acid ethyl ester compounds. The major volatile compound (compound 2) of the extracts produced fragment ions of 57, 70, 82, 98, 114 and $124 \mathrm{~m} / \mathrm{z}$ (Figure 2, Table 3) and was tentatively identified as nonanal. Second major volatile compound contributed $21 \%$ of the stem and $16.8 \%$ of the flower extract, which produced fragment ions of 55, 70,83,97, 121 and $166 \mathrm{~m} / \mathrm{z}$. With regards to fatty acid compounds, the major compound was identified as palmitic acid ethyl ester, which produced 55, 88, 101, 115, 157, 241 and $284 \mathrm{~m} / \mathrm{z}$ and had contributions of $17.2 \%$ and $9.3 \%$ for stem and flower extracts, respectively (Table 3, Figure 2).

Table 3. Volatile and fatty acid composition

\begin{tabular}{lllllllc}
\hline No & $\begin{array}{l}\text { Retention } \\
\text { time }\end{array}$ & $\begin{array}{l}\text { Name of } \\
\text { compound }\end{array}$ & $\begin{array}{l}\text { Molecular } \\
\text { formula }\end{array}$ & $\begin{array}{l}\text { Molecular } \\
\text { mass }\end{array}$ & Fragment ions & \multicolumn{2}{c}{$\begin{array}{c}\text { Relative } \\
\text { concentration (\%) }\end{array}$} \\
\hline 1 & 16.3 & Octanal & $\mathrm{C}_{8} \mathrm{H}_{16} \mathrm{O}$ & 128 & $57,69,81,84,100,110$ & 11.12 & 2.92 \\
2 & 19.4 & Nonanal & $\mathrm{C}_{9} \mathrm{H}_{18} \mathrm{O}$ & 142 & $57,70,82,98,114,124$ & 23.85 & 17.46 \\
3 & 21.6 & Isophorone & $\mathrm{C}_{9} \mathrm{H}_{14} \mathrm{O}$ & 138 & $54,82,95,123,138$ & $\mathrm{~T}$ & 2.83 \\
4 & 21.7 & 2-Nonenal & $\mathrm{C}_{9} \mathrm{H}_{16} \mathrm{O}$ & 140 & $55,70,83,96,111,122$ & $\mathrm{~T}$ & 3.39 \\
5 & 23.6 & Safranal & $\mathrm{C}_{10} \mathrm{H}_{14} \mathrm{O}$ & 150 & $51,65,91,107,121$, & ND & 2.37 \\
& & & & & 135,150 & & \\
6 & 24.6 & 2-Decenal & $\mathrm{C} 10 \mathrm{H} 18 \mathrm{O}$ & 154 & $55,70,83,98,110,136$ & 18.85 & 14.74 \\
\hline
\end{tabular}


Table 3. Continuing

\begin{tabular}{|c|c|c|c|c|c|c|c|}
\hline No & $\begin{array}{l}\text { Retention } \\
\text { time }\end{array}$ & $\begin{array}{l}\text { Name of } \\
\text { compound }\end{array}$ & $\begin{array}{l}\text { Molecular } \\
\text { formula }\end{array}$ & $\begin{array}{l}\text { Molecular } \\
\text { mass }\end{array}$ & Fragment ions & \multicolumn{2}{|c|}{$\begin{array}{c}\text { Relative } \\
\text { concentration (\%) }\end{array}$} \\
\hline 7 & 26.9 & 2,4-Decadienal & $\mathrm{C} 10 \mathrm{H} 16 \mathrm{O}$ & 152 & $67,81,95,123,152$ & $\mathrm{~T}$ & 4.41 \\
\hline 8 & 27.7 & 2-Undecenal & $\mathrm{C}_{11} \mathrm{H}_{20} \mathrm{O}$ & 168 & $55,70,83,97,121,166$ & 21.03 & 16.81 \\
\hline 9 & 31.6 & $\begin{array}{l}\text { 2,6-Di-tert- } \\
\text { butylphenol }\end{array}$ & $\mathrm{C}_{14} \mathrm{H}_{22} \mathrm{O}$ & 206 & $57,74,91,163,191,206$ & $\mathrm{~T}$ & 3.85 \\
\hline 10 & 40.2 & 2-Pentadecanone & $\mathrm{C}_{18} \mathrm{H}_{36} \mathrm{O}$ & 268 & $58,71,85,109,124$ & $\mathrm{~T}$ & 2.00 \\
\hline 11 & 42.2 & $\begin{array}{l}\text { Palmitic acid } \\
\text { methylester }\end{array}$ & $\mathrm{C}_{17} \mathrm{H}_{34} \mathrm{O}_{2}$ & 270 & $\begin{array}{l}55,74,87,97,143,171 \\
199,227,270\end{array}$ & 4.13 & 2.1 \\
\hline 12 & 43.6 & $\begin{array}{l}\text { Palmitic acid } \\
\text { ethylester }\end{array}$ & $\mathrm{C}_{18} \mathrm{H}_{36} \mathrm{O}_{2}$ & 284 & $\begin{array}{l}55,88,101,115,157 \\
241,284\end{array}$ & 17.23 & 9.32 \\
\hline 13 & 48.5 & $\begin{array}{l}\text { Oleic acid } \\
\text { ethylester }\end{array}$ & $\mathrm{C}_{20} \mathrm{H}_{38} \mathrm{O}_{2}$ & 310 & $\begin{array}{l}55,69,88,97,155,180 \\
222,264,310\end{array}$ & 3.78 & 5.59 \\
\hline 14 & 48.6 & $\begin{array}{l}9,12- \\
\text { Octadecadienoic } \\
\text { acid, ethyl ester }\end{array}$ & $\mathrm{C}_{20} \mathrm{H}_{36} \mathrm{O}_{2}$ & 308 & $\begin{array}{l}55,67,95,164,220 \\
263,279,308\end{array}$ & $\mathrm{~T}$ & 9.90 \\
\hline 15 & 49.1 & $\begin{array}{l}\text { Linoelic acid } \\
\text { ethyl ester }\end{array}$ & $\mathrm{C}_{20} \mathrm{H}_{34} \mathrm{O}_{2}$ & 306 & $\begin{array}{l}55,67,79,95,108,121 \\
261,306\end{array}$ & $\mathrm{~T}$ & 1.73 \\
\hline
\end{tabular}

ND: not detected, T: traces.

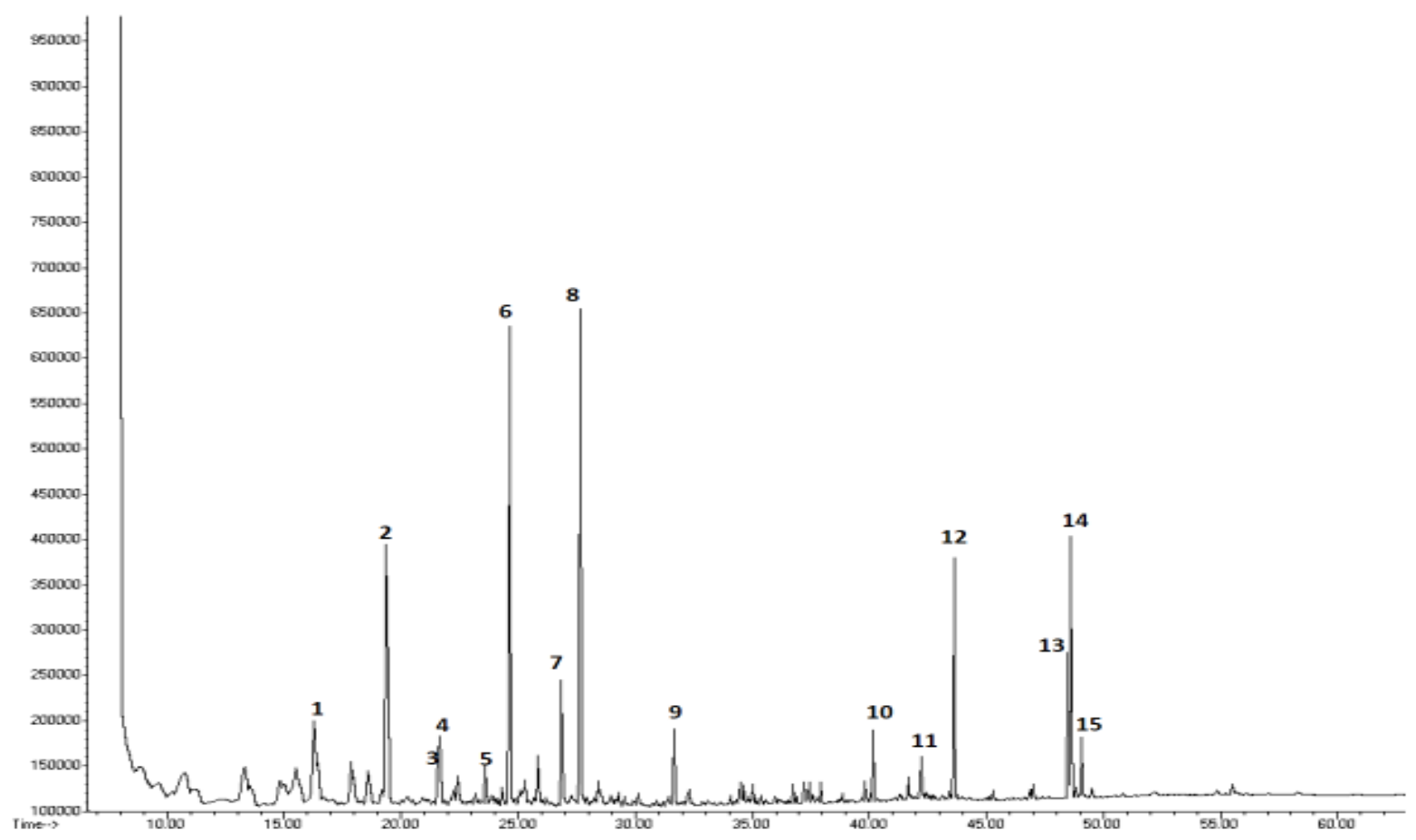

Figure 2. Representative GC-MS chromatogram of extracts: (1) Octanal, (2) Nonanal, (3) Isophorone, (4) 2-Nonenal, (5) Safranal, (6) 2-Decenal, (7) 2,4-Decadienal, (8) 2-Undecenal, (9) 2,6-Di-tertbutylphenol, (10) 2-Pentadecanone, (11) Palmitic acid methylester, (12) Palmitic acid ethylester, (13) Oleic acid ethylester, (14) 9, 12-Octadecadienoic acid, ethyl ester, (15) Linoleic acid ethyl ester. 


\section{DISCUSSION AND CONCLUSION}

Natural sources are rich in physiologically active antioxidant compounds such as phenolics, glycosides, volatiles, fatty acids, polysaccharides, carotenoids and alkaloids, which able to prevent and / or minimize the negative effects of oxidative stress. Antioxidant capacity of plant-based extracts can be assessed via complementary antioxidant testing methods representing two basic antioxidant mechanisms; hydrogen atom transfer (HAT) and single electron transfer (SET) mechanisms. ORAC values can be used as reference antioxidant effectiveness since it is able to measure the radical chain breaking ability of antioxidants by monitoring the inhibition of peroxyl radical-induced oxidation. In order to distinguishing dominant mechanisms for different antioxidants, addition to ORAC assay, reducing based antioxidant assays such as; FRAP assay for acidic condition and Folin-Ciocalteu method for alkaline condition are suggested to reveal the complementary antioxidant potential of plant based extracts [8]. Therefore within this study, ORAC assay represented HAT mechanism and FCR and FRAP tests represented SET mechanism were utilized. Luteolin hexoside rich stem extract had higher antioxidant capacity in SET mechanism assays, while verbascoside rich flower extract had higher antioxidant capacity in HAT mechanism.

Enzyme inhibitors isolated from natural sources are recognised as natural preventative medicines without or with a minimum side effect [6]. The stem extract which luteolin hexoside was the major phenolic compound was more potent of $\alpha$-glucosidase inhibition than that of the flower extract. This can be explained the amount of luteolin hexoside presence in the extracts since luteolin was reported as a potent $\alpha$-glucosidase inhibitory agent among various phenolic compounds [9]. On the other hand, flower extract had pronounced pancreatic lipase inhibitory activity that of the stem extract, which can be linked to the presence of verbascoside- a potent oxygen radical suppressing agent [10-11]. Verbascoside was reported to show significant antioxidant activities from bitter tea (Ligstrum purpurascens), a popular beverage in southern China [12]. Moreover, it was reported that Verbascoside had high antioxidant, antihaemolytic activities, as well as enzyme inhibitory activities [13]. Koo and co-authors reported that Acteoside (Verbascoside) and its aglycones effectively scavenge 1,1-diphenyl-2-picrylhydrazyl and nitric oxide in vitro [14]. Biological activities of luteolin and its glycosides and several possible mechanisms of action have been elucidated including scavenging of ROS (Reactive Oxygen Species), transition metal chelation, reducing oxidative stress and inflammation, induction of apoptosis, lowering glucose level, reducing the uptake of glucose, protection against radiation and antiinflammatory action [15-17]. Volatile and fatty acid compounds present in the extracts might be the secondary contributors of antioxidant activities, since they were reported as weak antioxidant agents [18]. High extraction yields of the extracts indicate the presence of high amounts of hydrophilic compounds. HPLC results showed that the hydrophilic compounds were one of the major chemical compounds present in the extracts. With regards volatile and fatty acid compounds, both of the extracts had similar and rich volatile and fatty acids composition.

The stem and flower extracts had pronounced antioxidant and enzyme inhibitory activities and contained high amount of phenolic and volatile compounds. The utilization of Verbascum cheiranthifolium var. cheiranthifolium in folk medicine for a wide range of ailments treatment can be explained by significant and effective biological activities and phytochemical compounds diversity. Our findings presented in this study might help to researchers to conduct further studies on endemic mullein species in order to explore natural health attributing agents.

\section{Acknowledgements}

The authors are grateful to the Van Yuzuncu Yil University Grant Commission for providing financial assistance of the research (Project number: THD-2017-6381). 


\section{Conflict of Interests}

Authors declare that there is no conflict of interests.

\section{ORCID}

\section{Abdullah Dalar (iD) https://orcid.org/0000-0002-0080-2519}

\section{REFERENCES}

[1]. Tatl1, İ.̇̇., Akdemir, Z.Ş. (2004). Chemical constituents of Verbascum L. species, FABAD Journal of Pharmaceutical Sciences, 29, 93-107.

[2]. Mükemre, M., Behçet, L., Çakılcıoğlu, U. (2015). Ethnobotanical study on medicinal plants in villages of Çatak (Van-Turkey), Journal of Ethnopharmacology, 166, 361-374.

[3]. Dalar, A., Guo, Y., Konczak, I. (2014). Phenolic composition and potential anti inflammatory properties of Verbascum cheiranthifolium var. cheiranthifolium leaf, Journal of Herbal Medicine, 4(4), 195-200.

[4]. Tatlı, İ.İ., Akdemir, Z.Ş. (2006). Traditional uses and biological activities of Verbascum species, FABAD Journal of Pharmaceutical Sciences, 31, 85-96.

[5]. Küçük, S., Özdemir, F., İşcan, G., İncesu, Z. (2016) Determination of Cytotoxic and Anticandidal Activities of Three Verbascum L. Species from Turkey: V. cheiranthifolium Boiss. var. asperulum (Boiss.) Murb. Monorg., V. pycnostachyum Boiss. \& Heldr and V. orgyale Boiss. \& Heldr., Turkish Journal of Pharmaceutical Sciences, 13(3), 318-322.

[6]. Dalar, A., Konczak, I. (2013). Phenolic contents, antioxidant capacities and inhibitory activities against key metabolic syndrome relevant enzymes of herbal teas from Eastern Anatolia, Industrial Crops and Products, 44, 383-390.

[7]. Uzun, Y., Dalar, A., Konczak, I. (2017). Sempervivum davisii: phytochemical composition, antioxidant and lipase-inhibitory activities, Pharmaceutical Biology, 55(1), 532-540.

[8]. Shahidi F., Zhong Y. (2015). Measurement of antioxidant activity, Journal of Functional Foods, 18, 757-781.

[9]. Tadera, K., Minami, Y., Takamatsu, K., Matsuoka, T. (2006). Inhibition of $\alpha$-glucosidase and $\alpha$-amylase by flavonoids, Journal of Nutritional Science and Vitaminology, 52(2), 149-153.

[10]. Aldini, G., Piccoli, A., Beretta, G., Morazzoni, P., Riva, A., Marinello, C., Facino, R.M. (2006). Antioxidant activity of polyphenols from solid olive residues of cv Coratina, Fitoterapia, 77(2), 121-128.

[11]. Piné, R., Herranz-López, M., Funes, L., Borrás-Linares, I., Micol, V., Segura-Carretero, A., Fernández- Gutiérrez, A. (2013). Phenylpropanoids and their metabolites are the major compounds responsible for blood-cell protection against oxidative stress after administration of Lippia citriodora in rats, Phytomedicine, 20(12), 1112-1118.

[12]. Wong, I.Y.F., He, Z.D., Huang, Y., Chen, Z.Y. (2001). Antioxidative activities of phenylethanoid glycosides from Ligustrum purpurascens, Journal of Agricultural and Food Chemistry, 49, 3113-3119.

[13]. Chen, C.H., Lin, Y.S., Chien, M.Y., Hou, W.C., Hu, M.L. (2012). Antioxidant and antihypertensive activities of acteoside and its analogs. Botanical Studies, 53, 421-429.

[14]. Koo, K.A., Kim, S.H., Oh, T.H., Kim, Y.C. (2006). Acteoside and its aglycones protect primary cultures of rat cortical cells from glutamate-induced excitotoxicity. Life Sciences, 79, 709-716. 
[15]. Manju, V., Balasubramaniyan, V., Nalini, N. (2005). Rat colonic lipid peroxidation and antioxidant status: the effect of dietary luteolin on 1, 2-dimethylhydrazine challenge, Cellular and Molecular Biology Letters, 10, 535-551.

[16]. Chen, C.Y., Peng, W.H., Tsai, K.D., Hsu, S.L. (2007). Luteolin supresses inflammationassociated gene expression by blocking NF-kappaB and AP-1 activation pathway in mouse alveolar macrophages, Life Sciences, 81, 1602-1614.

[17]. López-Lázaro, M. (2009). Distribution and Biological Activities of the Flavonoid Luteolin, Mini Reviews in Medicinal Chemistry, 9, 31-59.

[18]. Ruberto, J., Baratta, M.T. (2000). Antioxidant activity of selected essential oil components in two lipid model systems, Food Chemistry, 69, 167-74. 